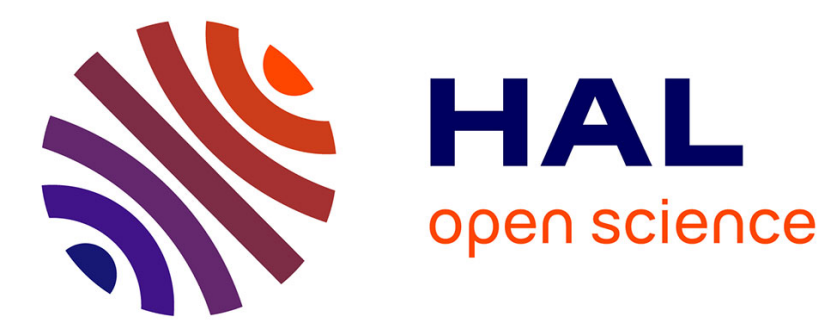

\title{
Bayesian Monte Carlo analysis applied to regional-scale inverse emission modeling for reactive trace gases
}

\author{
Laurent Deguillaume, M. Beekmann, L. Menut
}

\section{To cite this version:}

Laurent Deguillaume, M. Beekmann, L. Menut. Bayesian Monte Carlo analysis applied to regionalscale inverse emission modeling for reactive trace gases. Journal of Geophysical Research, 2007, 112 (D2), 10.1029/2006jd007518 . hal-01993846

\section{HAL Id: hal-01993846 \\ https://hal.uca.fr/hal-01993846}

Submitted on 7 Feb 2019

HAL is a multi-disciplinary open access archive for the deposit and dissemination of scientific research documents, whether they are published or not. The documents may come from teaching and research institutions in France or abroad, or from public or private research centers.
L'archive ouverte pluridisciplinaire HAL, est destinée au dépôt et à la diffusion de documents scientifiques de niveau recherche, publiés ou non, émanant des établissements d'enseignement et de recherche français ou étrangers, des laboratoires publics ou privés. 


\title{
Bayesian Monte Carlo analysis applied to regional-scale inverse emission modeling for reactive trace gases
}

\author{
L. Deguillaume, ${ }^{1}$ M. Beekmann, ${ }^{1}$ and L. Menut ${ }^{2}$ \\ Received 17 May 2006; revised 1 August 2006; accepted 4 August 2006; published 27 January 2007.
}

[1] The purpose of this article is inverse modeling of emissions at regional scale for photochemical applications. The study is performed for the Ile-de-France region over a two summers (1998 and 1999) period. This area represents an ideal framework since concentrated anthropogenic emissions in the Paris region frequently lead to the formation of urban plumes. The inversion method is based on Bayesian Monte Carlo analysis applied to a regional-scale chemistry transport model, CHIMERE. This method consists in performing a large number of successive simulations with the same model but with a distinct set of model input parameters at each time. Then a posteriori weights are attributed to individual Monte Carlo simulations by comparing them with observations from the AIRPARIF network: urban $\mathrm{NO}$ and $\mathrm{O}_{3}$ concentrations and rural $\mathrm{O}_{3}$ concentrations around the Paris area. For both $\mathrm{NO}$ and $\mathrm{O}_{3}$ measurements, observations used for constraining Monte Carlo simulations are additionally averaged over the time period considered for analysis. The observational constraints strongly reduce the a priori uncertainties in anthropogenic NOx and volatile organic compounds (VOC) emissions: (1) The a posteriori probability density function (pdf) for NOx emissions is not modified in its average, but the standard deviation is decreased to around $20 \%$ ( $40 \%$ for the a priori one). (2) VOC emissions are enhanced $(+16 \%)$ in the a posteriori pdf's with a standard deviation around $30 \%$ (40\% for the a priori one). Uncertainties in the simulated urban NO, urban $\mathrm{O}_{3}$, and $\mathrm{O}_{3}$ production within the plume are reduced by a factor of 3.2, 2.4, and 1.7, respectively.

Citation: Deguillaume, L., M. Beekmann, and L. Menut (2007), Bayesian Monte Carlo analysis applied to regional-scale inverse emission modeling for reactive trace gases, J. Geophys. Res., 112, D02307, doi:10.1029/2006JD007518.

\section{Introduction}

[2] Air quality simulation and forecasting is a challenging scientific and society-related problem due to the increasing consciousness of health and environmental effects of photooxidants and particles. Nitrogen oxides (NOx) and volatile organic compounds (VOC) are, among others, very important precursors of this pollution.

[3] During the last decade, modeling tools have been increasingly developed allowing for a better description of photochemical air pollution episodes, but also for multiyear simulations. These models combine mathematical descriptions of atmospheric physics and chemistry, accounting for emissions, transport, photochemical reactions and deposition and have been mostly used to assess the effect of proposed control strategies for urban and regional pollution. In this framework, the CHIMERE chemistry/transport model (CTM) has been developed with two main objectives: (1) to build realistic emission reduction scenario simulations

\footnotetext{
${ }^{1}$ Laboratoire Inter-Universitaire des Systèmes Atmosphériques, UMR CNRS 7583, Universités Paris 7 et Paris 12, Créteil, France.

${ }^{2}$ Institut Pierre Simon Laplace/Laboratoire de Météorologie Dynamique, Ecole Polytechnique, Palaiseau, France.

Copyright 2007 by the American Geophysical Union. 0148-0227/07/2006JD007518
}

to better estimate how pollution can be reduced [e.g., Vautard et al., 2005]; (2) but also to forecast of air pollution events several days in advance [Vautard et al., 2001] (http:// www.prevair.ineris.fr). However, uncertainties in model input data and parameterizations need to be quantified in order to obtain more robust modeled concentrations fields.

[4] Uncertainty in deterministic atmospheric transport models is related to many factors: (1) uncertainties in input parameters such as meteorological parameters, actinic fluxes, quantum yields, rate constants, and, last but not least, emissions of anthropogenic and biogenic volatile organic compounds (VOC) and nitrogen oxides (NOx) [Yang et al., 1997; Gao et al., 1996; Sistla et al., 1996; Hanna et al., 1998; Bergin and Milford, 2000; Menut et al., 2000; Hanna et al., 2001; Beekmann and Derognat, 2003]; (2) uncertainties in model physical and chemical processes description such as the boundary layer height parametrization and resolution or the formulation of the chemical mechanism [Kuhn et al., 1998].

[5] Moreover, all these modeling studies converge toward an important statement: within a chemistry transport model, emissions from the surface are crucial but also uncertain input parameters, for which simulated concentrations are very sensitive. The adjoint modeling version of the CHIMERE model makes it possible to systematically scan the sensitivity of the pollutant concentrations compared to the 
various parameters of the model. In a study dealing with a photochemical pollution episode during the ESQUIF campaign emissions are shown to be among the most determining parameter for the ozone production over the Ile-de-France area [Menut, 2003]. From Monte Carlo analysis systematically exploring the effect of model input uncertainties on photochemical ozone build-up $\left(\mathrm{PO}_{3}\right)$ in the Ile-de-France region [Beekmann and Derognat, 2003], it is also concluded that VOC and NOx emissions were about the most uncertain and sensitive input parameters: $43-53 \%$ of the total uncertainty in $\mathrm{PO}_{3}$ were related to emission uncertainty, $18-25 \%$ to that in meteorological parameters and $16-23 \%$ to that in rate coefficients.

[6] Moreover, uncertainty in emissions is always rather large, and difficult to estimate. Indeed, emission inventories are built following a "bottom up" methodology. Activity factors for different sectors are combined with compound and activity specific emission factors. While geographical locations of large point sources are known, diffuse area emissions are in general estimated for administrative districts and have to be distributed on regular spatial grids used for modeling purposes. For traffic emissions, spatialization relies on the knowledge of the road network and traffic fluxes. Also the temporal variability at seasonal, weekly or daily scale has to be taken into account. All these different terms (activity factor, emission factor spatial distribution, and temporal variability) have specific uncertainties which may combine to a large overall value [Schneider et al., 1997; Friedrich, 1997; Kühlwein and Friedrich, 2000].

[7] Evaluation of emission inventories is in general difficult as emitted pollutants undergo chemical transformation and are transported away from sources. Only for special cases with concentrated emissions in an urban agglomeration surrounded by rural areas with very low emissions, specific evaluation experiments could be performed on the basis of circular flights around the main source of emissions (Slemr et al. [2002] for the Augsburg area, Vautard et al. [2003b] for the Paris agglomeration).

[8] Inverse modeling of emissions from ground based and satellite observations is a potentially powerful method for evaluating and improving the emission inventories. All techniques of inverse emission modeling are based on the minimisation of a cost function which describes the difference between a set of observations and the corresponding simulations. This minimisation step is achieved by varying emissions while starting with an a priori guess of emissions. At regional scale, only a limited number of studies have been performed: Some applications have applied direct matrix inversion techniques [Brown, 1993] to adjust emissions of low-reactive species. Mulholland and Seinfeld [1995] and Chang et al. [1996, 1997] have used a Kaman filter approach to optimize isoprene and $\mathrm{CO}$ emissions. Kalman filtering is a sequential method based on a linear relationship between modification of constraints (observations) and model parameters during the same time period [Hartley and Prinn, 1993; Enting, 2002]. Variational assimilation techniques vary initial conditions or model parameters as emissions to obtain a better agreement of simulations and observations over a given time window. The adjoint model is used to solve the minimization problem [Elbern et al., 1997; Elbern and Schmidt, 1999; Quélo et al., 2005; Pison et al., 2006]. For example, Pison et al. [2006] use the adjoint version of the CHIMERE chemistry transport model in order to retrieve NOx emissions fluxes over the Ile-de-France region from NO surface measurements. In a similar framework, Quélo et al. [2005] optimized NOx emissions over the Lille region (northern France) by using routine measurements of $\mathrm{O}_{3}$, $\mathrm{NO}$ and $\mathrm{NO}_{2}$. Finally, Mendoza-Dominguez and Russell [2000, 2001] use a hybrid modeling approach based upon application of direct sensitivity analysis to a comprehensive 3D air quality model linked to a receptor analysis method. Their works lead to an optimization of VOC and NOx sources during the 1992 Atlanta measurements. However, all of these approaches make the hypothesis of a perfect model with perfect model input parameters other than emissions.

[9] In this paper, we use Bayesian Monte Carlo (BMC) analysis [Brand and Small, 1995; Bergin and Milford, 2000; Beekmann and Derognat, 2003] in order to retrieve anthropogenic NOx and VOC emissions in the Ile de France region. The particular strength of the BMC method is that it allows estimating the uncertainty in a posteriori emissions by taking into account both the uncertainty in model input parameters and in constraining observations. In our framework, a Monte Carlo analysis consists of performing a large number of successive simulations with the same model but with a distinct set of model input parameters sampled from probability distributions reflecting the uncertainty in these input parameters. Simulations which better fit observations receive a larger weight; that is, in Bayesian terms they have a larger conditional probability. Indeed, a likelihood function quantifies the probability of obtaining a given difference between model results and observations, while taking into account a specified error in the observations.

[10] In the present work, we perform an inverse modeling study of anthropogenic NOx and VOC emissions for the Ilede-France region by means of Bayesian Monte Carlo (BMC) analysis. We use the regional-scale chemistry transport model CHIMERE [Schmidt et al., 2001; Vautard et al., 2001]. The Ile-de-France region represents an ideal framework because concentrated anthropogenic emissions in the Paris area frequently lead to the formation of urban plumes. Moreover, observations for constraining Monte Carlo simulations are numerous in time and space, both from routine measurements by the AIRPARIF air quality network or from a dedicated campaign (the ESQUIF campaign in 1998 and 1999) [Menut et al., 2000; Vautard et al., 2003a]. In this work, BMC analysis has been applied to semiclimatologic period (summers 1998 and 1999) characterized by frequent formation of ozone plumes over the Ilede-France basin.

[11] The paper is organized as follows: the CHIMERE chemistry/transport model is briefly described in section 2.1 and the setup of Bayesian Monte Carlo analysis for this study is presented in section 2.2. Results are shown in section 3. Section 3.1 is devoted to overall results for summers 1998 and 1999. Sections 3.2 and 3.3 analyse differences between summers 1998 and 1999, between particular months (July versus August) and the type of the day (working days versus week end). Section 4 is devoted 


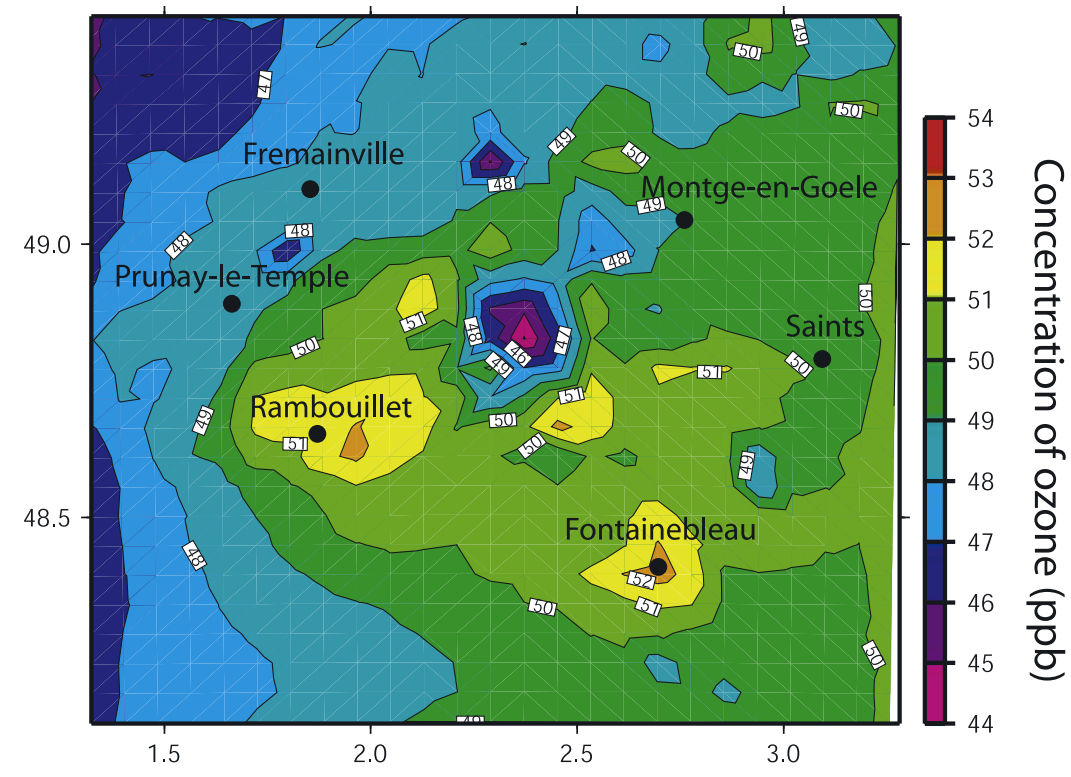

Figure 1. Distribution of the daily maximum of ozone in the nominal case averaged over the summers 1998 and 1999. Rural stations from the AIRPARIF network are indicated.

to a critical analysis of the results and conclusions are given in section 5 .

\section{Setup of the Bayesian Monte Carlo Analysis to the CHIMERE Chemistry/Transport Model}

\subsection{Model Description}

[12] The chemistry/transport model used in this study is the CHIMERE Eulerian multiscale model designed for analysis of various air pollution episodes at regional and continental scale [Vautard et al., 2001; Schmidt et al., 2001; Bessagnet et al., 2004] as well as for routine forecasting air pollution. Although the model enables modeling of gases and aerosols, this paper focuses on gas phase processes only. In the present study, the model calculates, given the emissions, meteorological variables and lateral boundary conditions, the concentration fields of several pollutants, on a $6 \times 6 \mathrm{~km}$ grid, over a domain of $150 * 150 \mathrm{~km}$ covering the Ile-de-France region. This domain has a large central urban area spreading over about $30 \mathrm{~km}$. The continental-scale version of CHIMERE provides boundary conditions for several long-lived species $\left(\mathrm{O}_{3}, \mathrm{NOy}, \mathrm{VOC}, \mathrm{CO}\right.$, peroxides etc.). In the vertical, the domain contains eight layers defined using hybrid coordinates. The height of the first layer is fixed at $50 \mathrm{~m}$ high and follows the orography and the top of the upper layer is fixed by a constant pressure level of $500 \mathrm{hPa}$.

[13] The CHIMERE transport chemistry simulations in this paper are forced by first-guess meteorological fields delivered by the European Centre for Medium-Range Forecasts (ECMWF) every 6 hours. Vertical diffusion is calculated using the parameterisation suggested by Troen and Mahrt [1986].

[14] The anthropogenic emissions for the Ile-de-France region and the year 1997 are prepared from several data sources and are described in detail by Vautard et al. [2003b]. NOx, VOC, $\mathrm{CO}$ and $\mathrm{SO}_{2}$ emissions were calcu- lated for three types of days (weekday, Saturday and Sunday) with a one hour temporal and a three kilometres spatial resolution by the "Système Informatique de Modélisation de la Pollution Atmosphérique à l'Echelle Régionale" (SIMPAR) [Vautard et al., 2003b]. Specific emissions profiles were provided for more than one hundred individual VOCs and for different activity sectors by the University of Stuttgart (Germany) [Friedrich, 1997]. The biogenic emissions (isoprene and terpene, $\mathrm{NO}$ ) inventory is described by Derognat et al. [2003].

[15] The gas phase chemistry is described by the MELCHIOR mechanism in a reduced version containing about 120 reactions and 40 compounds [Lattuati, 1997; Schmidt et al., 2001]. Eight model compounds are considered for alkanes, alkenes, aromatic and biogenic compounds with a related reactivity weighted as proposed by Middleton et al. [1990]. Photolysis rates are calculated using the tabulated outputs from the TUV model from Madronich and Flocke [1998] (tropospheric ultraviolet and visible model) and therefore depend on altitude, zenithal angle and cloud cover. Figure 1 represents the distribution of the daily maximum of ozone over the Ile de France domain for the whole time period (summers 1998 and 1999). In the urban area, daily ozone maxima are lower because of titration with NO emissions. Photochemical ozone build-up becomes apparent at several kilometres downwind of the urban area, especially in the southern direction. Rural stations from the AIRPARIF network have been set up in these regions (see Figure 1).

[16] The reliability of the CHIMERE model over the Ilede-France region has been evaluated on the basis of longterm routine air quality network measurements $\left(\mathrm{O}_{3}, \mathrm{NOx}\right)$ and observations from the ESQUIF campaign [see Vautard et al., 2001, 2003a]. A more detailed description of basic features of earlier model versions can be found in the papers from Schmidt et al. [2001] and Vautard et al. [2001]. Bessagnet et al. [2004] also presented important recent updates (in particular the implementation of the aerosol 


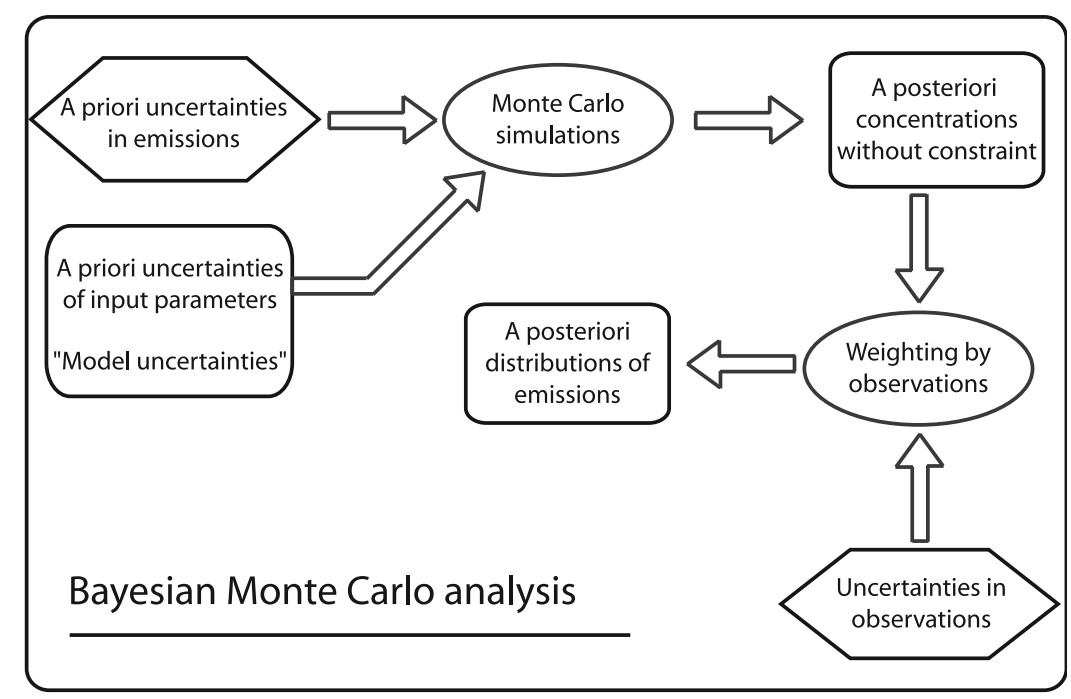

Figure 2. Principle of the Bayesian Monte Carlo Analysis.

module). A comprehensive scientific and technical documentation and the source codes are also available on the web (see http://euler.lmd.polytechnique.fr/chimere/).

\subsection{BMC Analysis}

\subsubsection{General Consideration}

[17] The BMC analysis applied in this study is adapted from the work of Bergin and Milford [2000] and has been previously applied to the photochemical air quality model CHIMERE by Beekmann and Derognat [2003]. In this last work, the BMC analysis has been used for specific POIs during the ESQUIF campaign whereas our study is led over a semiclimatologic period.

[18] Monte Carlo methods allow an evaluation of the global model uncertainty related to the whole set of input variables or parameterizations used. These methods consist in generating several hundreds of simulations with different sets of model input parameters. These sets are randomly selected from predefined probability density functions. In standard Monte Carlo analysis, model results that match the observations and those in poor agreement with them are treated as equally probable. An extension of this method, called "Bayesian Monte Carlo analysis", introduces a forcing by the observations allowing estimating the probability of each Monte Carlo simulation from the agreement between model output and observations [Dilks et al., 1992; Brand and Small, 1995] (Figure 2).

[19] The Bayesian method consists in evaluating the probability term $\mathrm{p}\left(\mathrm{O} \mid \mathrm{Y}_{\mathrm{k}}\right)$ corresponding to the probability to observe a vector of observations $\mathrm{O}$ given that the model output $Y_{k}$ is the true value for the kth individual Monte Carlo simulation. Assuming the observations to be unbiased and to present a normally distributed error $\varepsilon$ and for the case of $\mathrm{N}$ independent observations $\mathrm{O}_{\mathrm{j}}$, elements of a vector of observation $\mathrm{O}$, the agreement function $\mathrm{p}\left(\mathrm{O} \mid \mathrm{Y}_{\mathrm{k}}\right)$ can be evaluated as following:

$$
\mathrm{p}\left(\mathrm{O} \mid \mathrm{Y}_{\mathrm{k}}\right)=\Pi_{\mathrm{j}=1, \mathrm{~N}}\left(\frac{1}{\sqrt{2 \pi}} \frac{1}{\sigma_{\varepsilon, \mathrm{j}}} \times \exp \left(-0.5\left[\frac{\mathrm{O}_{\mathrm{j}}-\mathrm{Y}_{\mathrm{k}, \mathrm{j}}}{\sigma_{\varepsilon, \mathrm{j}}}\right]^{2}\right)\right)
$$

For mathematical details of the derivation of this function, see Bergin and Milford [2000], and Beekmann and Derognat [2003].

[20] In equation (1), the difference between simulations and observations is weighted by uncertainties $\sigma_{\varepsilon}, \mathrm{j}$ in observations, which have to be estimated (see section 2.2.4). The error $\varepsilon$ stems both from a purely experimental error and from the fact that point measurements are not necessarily representative for simulated averages over a model grid cell [Bergin and Milford, 2000]. In other words, point measurements can be considered as individual samples from a distribution of hypothetical measurements filling out the whole grid cell.

[21] Equation (1) allows obtaining a posteriori probability distributions of predictive model parameters from the ensemble of Monte Carlo simulations, by weighting each value by the probability $\mathrm{p}(\mathrm{O} \mid \mathrm{Yk})$. Also for each model input variable e, such as emissions, a distribution of their a posteriori probability can be obtained by weighting each value from the a priori distribution by $\mathrm{p}(\mathrm{O} \mid \mathrm{Yk})$ :

$$
p\left(e_{1} \leq e \leq e_{2}\right)=\frac{1}{C} \int_{e_{1}}^{e_{2}} p\left(O \mid Y_{k}\right) \cdot d e
$$

The probability $\mathrm{p}\left(\mathrm{e}_{1} \leq \mathrm{e} \leq \mathrm{e}_{2}\right)$ to find a value e between $\mathrm{e}_{1}$ and $\mathrm{e}_{2}$ is given by integrating $\mathrm{p}(\mathrm{O} \mid \mathrm{Yk})$ over all Monte Carlo simulations with emissions between $\mathrm{e}_{1}$ and $\mathrm{e}_{2}(\mathrm{C}$ represents a normalization factor).

[22] In this work, all perturbative factors applied in BMC analysis are averaged over the whole model domain and time period of the simulations. As a consequence, rather than hourly emissions for each grid cell, area and time averaged corrective factors for emissions are obtained in this work, together with their uncertainty estimate. This limitation to spatial average correction factors is necessary because observations are available only at several tenths of sites within the domain, and they have to be further averaged to obtain spatially representative values (see section 2.2.3). The limitation to temporally averaged correction factors (for summers 1998 and 1999 or subsets 
Table 1. Uncertainty Range Adopted for Model Input Parameters

\begin{tabular}{|c|c|}
\hline Parameters & $1 \sigma$ Uncertainty \\
\hline \multicolumn{2}{|c|}{ Emissions } \\
\hline Anthropogenic VOC & $\pm 40 \%$ \\
\hline Anthropogenic NOx & $\pm 40 \%$ \\
\hline Biogenic VOC & $\pm 50 \%$ \\
\hline \multicolumn{2}{|c|}{ Rate Constants } \\
\hline $\mathrm{NO}+\mathrm{O}_{3}$ & $\pm 10 \%$ \\
\hline $\mathrm{NO}_{2}+\mathrm{OH}$ & $\pm 10 \%$ \\
\hline $\mathrm{NO}+\mathrm{HO}_{2}$ & $\pm 10 \%$ \\
\hline $\mathrm{NO}+\mathrm{RO}_{2}$ & $\pm 30 \%$ \\
\hline $\mathrm{HO}_{2}+\mathrm{HO}_{2}$ & $\pm 10 \%$ \\
\hline $\mathrm{RO}_{2}+\mathrm{HO}_{2}$ & $\pm 30 \%$ \\
\hline $\mathrm{RH}+\mathrm{OH}$ & $\pm 10 \%$ \\
\hline $\mathrm{CH}_{3} \mathrm{COO}_{2}+\mathrm{NO}$ & $\pm 20 \%$ \\
\hline $\mathrm{CH}_{3} \mathrm{COO}_{2}+\mathrm{NO}_{2}$ & $\pm 20 \%$ \\
\hline $\mathrm{PAN}+\mathrm{M}$ & $\pm 30 \%$ \\
\hline \multicolumn{2}{|c|}{ Photolysis Frequencies and Radiation } \\
\hline Actinic fluxes & $\pm 10 \%$ \\
\hline $\mathrm{J}\left(\mathrm{O}_{3} \rightarrow 2 \mathrm{OH}\right)$ & $\pm 30 \%$ \\
\hline $\mathrm{J}\left(\mathrm{NO}_{2} \rightarrow \mathrm{NO}+\mathrm{O}_{3}\right)$ & $\pm 20 \%$ \\
\hline $\mathrm{J}\left(\mathrm{CH}_{2} \mathrm{O} \rightarrow \mathrm{CO}+2 \mathrm{HO}_{2}\right)$ & $\pm 40 \%$ \\
\hline $\mathrm{J}\left(\mathrm{CH}_{3} \mathrm{COCO} \rightarrow \ldots\right)$ & $\pm 50 \%$ \\
\hline $\mathrm{J}($ unsaturated carbonyl $\rightarrow \ldots$ ) & $\pm 40 \%$ \\
\hline \multicolumn{2}{|c|}{ Meteorological Parameters } \\
\hline Zonal wind speed & $\pm 1 \mathrm{~m} / \mathrm{s}$ \\
\hline Meridional wind speed & $\pm 1 \mathrm{~m} / \mathrm{s}$ \\
\hline Mixing layer height & $\pm 40 \%$ \\
\hline Temperature & $\pm 1.5 \mathrm{~K}$ \\
\hline Relative humidity & $\pm 20 \%$ \\
\hline Vertical mixing coefficient & $\pm 50 \%$ \\
\hline \multicolumn{2}{|c|}{ Others } \\
\hline Deposition velocity & \pm 25 \\
\hline
\end{tabular}

of this period) is motivated by the fact that in this way the measurement representativity error is reduced (see section 2.2.4).

[23] The results of BMC analysis are presented in two different ways. First, we will show how a posteriori probability density functions (called pdf's afterward) have been modified with respect to a priori pdf's by using the measurement constraint. Secondly, results are presented as cumulative probability density functions (cpdf's). The term $\operatorname{cpdf}(\mathrm{X})$ indicates the probability that a given model prediction $\mathrm{X}_{\mathrm{k}}$ stays below the limit $\mathrm{X} . \mathrm{X}_{\mathrm{k}}$ can represent any model output variables, for example the ozone level at a particular grid point, but also model input parameters as emissions.

2.2.2. Attribution of the "A Priori" Probability Density Functions for Input Parameters

[24] A tricky problem for the setup of Monte Carlo analysis is related to the choice of a priori pdf's for the input model parameters, i.e., for emissions, rate coefficients of chemical reactions and photolysis frequencies, and for meteorological parameters. The most natural form, for pdf's containing only positive values, is the lognormal distribution which was considered for all the input parameters except for wind speed and temperature. Indeed, lognormal pdf's best represent uncertainties for positively defined entities which are affected by many independent stochastic processes, varying over a large range. The choice of uncertainty ranges (Table 1) bas been guided by specific uncertainty assessment studies and expert judgements. A detailed description of the determination of a priori pdf's is given by Beekmann and Derognat [2003]. In this section, only features which are the most important in the context of the given study are mentioned.

[25] Regarding anthropogenic emissions, studies on the uncertainty propagation of uncertainties in emission models [Kühlwein and Friedrich, 2000], specific experiments on the estimation of emissions from observations in the Ile-deFrance region [Vautard et al., 2003b] and in the South of Germany [Kühlwein et al., 2002; Mannschreck et al., 2002] were considered in order to estimate their one sigma uncertainty range at $40 \%$.

[26] On the basis of the sensitivity analysis performed by Menut [2003], only the uncertainties in the most sensitive reactions for ozone and nitrogen chemistry were included in the Monte Carlo experiment. The uncertainties from the compilations of Atkinson et al. [1997] and DeMore et al. [1997] were used. They indicate values for uncertainties ranging from 10 to $30 \%$. Uncertainties in meteorological variables are derived from the random differences between observations and meteorological analyses for two POIs of the ESQUIF campaign [Menut et al., 2000; Vautard et al., 2003a]. For example, uncertainty in the boundary layer height is set to $40 \%$, corresponding to the important differences noted between heights estimated from meteorological data (by calculating vertical profiles of the Richardson number) and used for CHIMERE simulations and derived from lidar profiles (aerosol backscatter signal).

[27] In the present study, we only focus on model uncertainties specifically related to dynamical and chemical processes within the Paris urban area plume. As a consequence, we have chosen not to perform an uncertainty analysis for the continental model domain of for the boundary conditions passed form the continental model to the regional nested model.

\subsubsection{Measurement Constraints}

[28] In order to be useful for inverse modeling purposes, the observations used for constraining Monte Carlo simulations must contain a maximum of information on anthropogenic NOx and VOC emissions emitted in the Paris area and its suburbs. For this, measurements of NO containing direct information on NOx emissions and ozone measurements, containing indirect information especially on VOC emissions via the ozone photochemical production process, were used. Moreover, the observations must ideally take place at a certain distance from the emission sources in order to get rid of their spatial heterogeneity. Lastly, measurements must allow evaluating the background concentrations of pollutants in order to identify the part related to sources.

[29] In this study for the summers 1998 and 1999 period, the observations available for constraining Monte Carlo simulations are routine measurements from the AIRPARIF air quality network. The observation vector $\mathbf{O}$ in equation (1) is built from three different types of observations: (1) ground based NO measurements within the urban area (Paris and near suburbs), (2) ground based $\mathrm{O}_{3}$ measurements at the same places, (3) ground based $\mathrm{O}_{3}$ measurements around the Paris area (rural sites), either located within the pollution plume or indicating background conditions, as a function of the wind direction.

[30] NO concentrations at these six background urban sites within Paris and its near suburbs during morning 


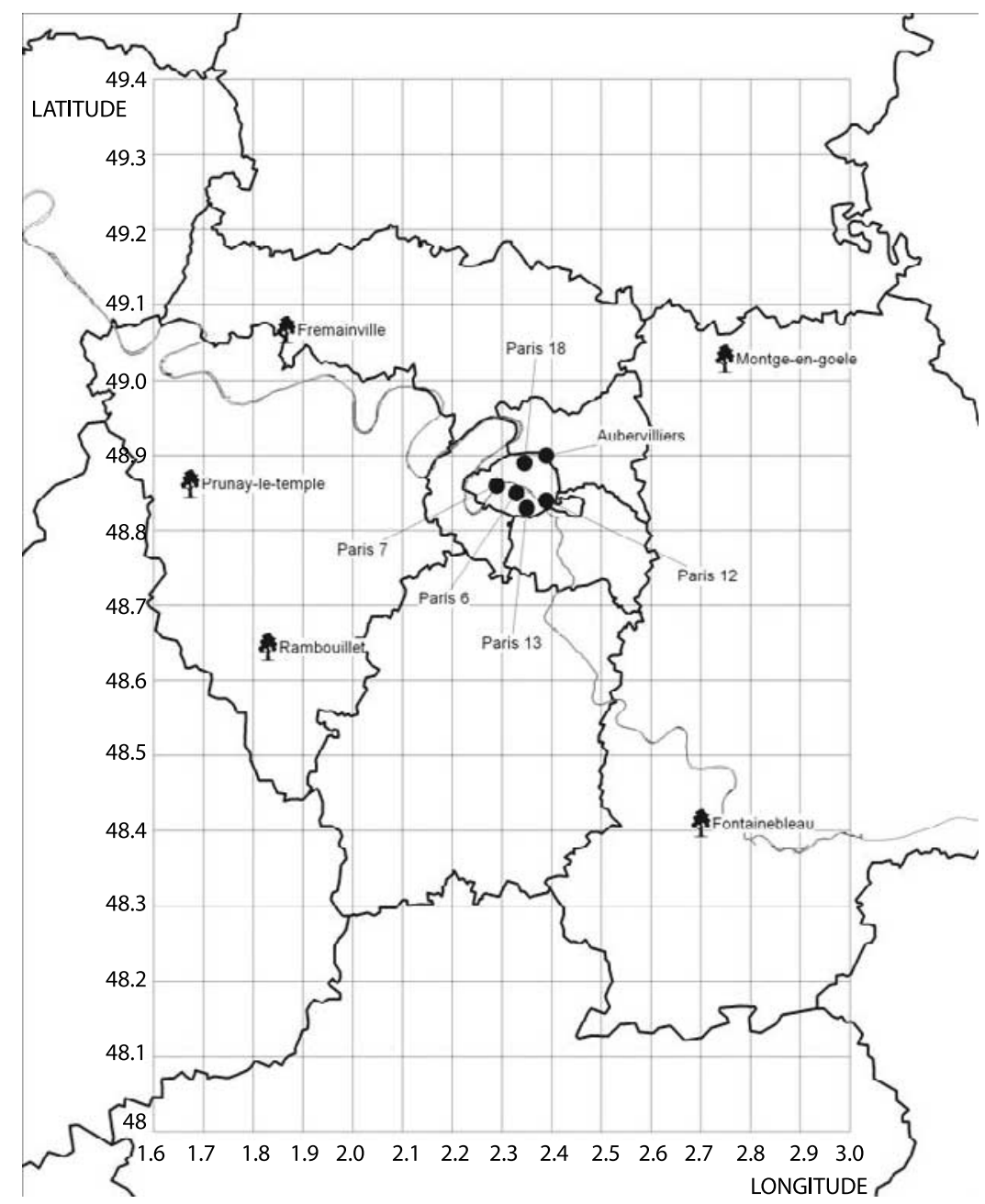

Figure 3. Locations of urban and rural background sites of the AIRPARIF network used for the model constraints (tree symbol: rural stations; circle: urban stations).

(03:00-09:00 UTC) (Figure 3) were combined to give an average urban morning mean value. The use of an average morning mean value (1) minimizes measurement errors since NO concentrations are most elevated during this time (because of the traffic-related morning emission maximum combined to weak vertical mixing), and (2) is more robust than hourly values with respect to model errors in the temporal representation of the planetary boundary layer height. Urban NO measurements are closely related to NO sources and therefore are a direct forcing for NOx emissions.

[31] Second, surface ozone measurements are averaged over the same six background urban sites, but this time during afternoon hours (12:00-16:00 UTC). The afternoon values are affected by photochemical ozone build-up and thus contain information on ozone precursor emissions (VOC, NOx). For both urban $\mathrm{NO}$ and $\mathrm{O}_{3}$ measurements, observations used for constraining Monte Carlo simulations are additionally averaged over the time period considered for analysis (summers $1998+1999$ or subsets):

$$
O B S\left(N O, O_{3}\right)=\frac{1}{N d \cdot N s \cdot N h}\left(\sum_{k=1}^{N d} \sum_{j=1}^{N s} \sum_{i=1}^{N h} o b s(i, j, k)\right)
$$

with $\mathrm{Nd}=$ number of days, $\mathrm{Ns}=$ number of stations, $\mathrm{Nh}=$ number of hours and obs $(\mathrm{i}, \mathrm{j}, \mathrm{k})=$ hourly observations from the AIRPARIF network. The same procedure was followed for simulations, taking averages over the grid cells and dates corresponding to the measurement sites.

[32] The third constraint is linked to $\mathrm{O}_{3}$ measurements at six rural AIRPARIF stations. It consists in determining a daily ozone build-up within the Ile-de-France region from the difference between plume and background ozone concentrations. First, for each day, and both for simulations and observations, we extract the daily $\mathrm{O}_{3}$ maximum. Then, we take the average of the two largest values which are considered as representative for the $\mathrm{O}_{3}$ plume and the average of the lowest tree values which represents the $\mathrm{O}_{3}$ background value. In order to take into account errors in the simulated location of the plume (caused by errors in the wind direction), the procedure is performed independently for simulations and observations. However, only days for which the ozone maximum is observed and simulated at the same or a neighbouring station are retained for further analysis (i.e., days with wind direction errors larger than about $90^{\circ}$ are discarded). A second condition is set up in order to assure that only strong enough plumes are considered: the difference between the $\mathrm{O}_{3}$ daily maxima both in 
Table 2. One $\sigma$ Logarithmic Errors for Measurement Constraints and for Different Time Periods

\begin{tabular}{|c|c|c|}
\hline Measurement constraints & Period & $1 \sigma$ Logarithmic errors \\
\hline \multirow[t]{7}{*}{$\mathrm{O}_{3}{ }^{\text {plume }}-\mathrm{O}_{3}{ }^{\text {background }}$} & 1998 & 0.235 \\
\hline & 1999 & 0.291 \\
\hline & $1998+1999$ & 0.266 \\
\hline & July $1998+1999$ & 0.299 \\
\hline & August $1998+1999$ & 0.239 \\
\hline & working days & 0.262 \\
\hline & weekend $1998+1999$ & 0.278 \\
\hline \multirow[t]{7}{*}{ Urban NO } & 1998 & 0.331 \\
\hline & 1999 & 0.319 \\
\hline & $1998+1999$ & 0.308 \\
\hline & July $1998+1999$ & 0.357 \\
\hline & August $1998+1999$ & 0.314 \\
\hline & Working days & 0.287 \\
\hline & Weekend $1998+1999$ & 0.491 \\
\hline \multirow[t]{7}{*}{ Urban $\mathrm{O}_{3}$} & 1998 & 0.149 \\
\hline & 1999 & 0.112 \\
\hline & $1998+1999$ & 0.137 \\
\hline & July $1998+1999$ & 0.132 \\
\hline & August $1998+1999$ & 0.144 \\
\hline & Working days & 0.137 \\
\hline & Weekend $1998+1999$ & 0.131 \\
\hline
\end{tabular}

the plume and in the background must exceed $10 \mathrm{ppb}$ both in simulations and observations. As a consequence of this procedure, the number of selected days will slightly differ for each Monte Carlo simulation.

\subsubsection{Estimation of the Uncertainty on Observations}

[33] The solution of equation (1) requires the knowledge of uncertainty in observations. Different sources contribute to uncertainties $\sigma_{\varepsilon, 1}, \sigma_{\varepsilon}, 2, \sigma_{\varepsilon, 3}$ in observations $\mathrm{O}_{1}, \mathrm{O}_{2}, \mathrm{O}_{3}$ in equation (1). In a general way, this uncertainty stems both from instrumental errors and a lack of horizontal and vertical representativity of point measurements with respect to model grid cells. Thus variances related to instrumental error $\sigma_{\mathrm{i}}^{2}$, to the horizontal representativity $\sigma_{\mathrm{h}}^{2}$ and to the vertical representativity $\sigma_{\mathrm{v}}^{2}$ are combined to an overall uncertainty:

$$
\sigma^{2}=\sigma_{\mathrm{i}}^{2}+\sigma_{\mathrm{h}}^{2}+\sigma_{\mathrm{v}}^{2}
$$

All terms in equation (4) represent logarithmic uncertainties, and the subscript $\mathrm{j}$ for different types of observations has been omitted for simplicity. From these different sources on observation uncertainties, we estimated $1 \sigma$ logarithmic total uncertainties for the different time periods we considered summarizing in Table 2. Note that the uncertainties always refer to the temporal averages over these different time periods.

[34] For observations in the urban area, instrumental uncertainties are dominating over uncertainties due to representativity problems. Their values varies from 3 to $4 \mathrm{ppb}$ (see the ESQUIF report, 2002 at http://esquif.lmd. polytechnique.fr/) for $\mathrm{NO}$ and $\mathrm{O}_{3}$ measurements, and are relatively independent from the measured concentrations. Uncertainty in horizontal representativity was assessed by simply calculating the standard deviation of the average of $\mathrm{O}_{3}$ and $\mathrm{NO}$ values form the six urban surface sites. Besides, both for urban $\mathrm{O}_{3}$ and $\mathrm{NO}$ observations, a correction was applied to take into account the fact that measurements were performed at around $3 \mathrm{~m}$ height whereas simulations are representative for a layer between ground and $50 \mathrm{~m}$ height.
The corrective term was determined by comparison between observations at the first floor of the Eiffel tower (around $50 \mathrm{~m}$ height) with measurements performed near ground.

[35] Uncertainty in $\mathrm{O}_{3}$ production within the plume is composed both by uncertainties in plume and in background ozone concentration. For both of it, we therefore calculate instrumental and horizontal representativity uncertainties following equation (4). Variances related to errors on the spatial maximum of $\mathrm{O}_{3}$ and background $\mathrm{O}_{3}$ are combined to an overall uncertainty:

$$
\sigma^{2}=\sigma_{\max }^{2}+\sigma_{\text {back }}^{2}
$$

\subsubsection{Practical Setup of the BMC Experiment}

[36] First, 500 Monte Carlo simulations were performed by using the simple random sampling technique [Hanna et al., 1998]. For this, different model input parameter sets are generated by simultaneous and randomly varying all input parameters according to their probability density functions. With each of these 500 individual parameter data sets, 500 simulations were performed for July and August 1998 and 1999. Second, a posteriori weights were calculated for each Monte Carlo simulation, using equation (1), individually for each observational constraint $(\mathrm{N}=1)$ and for the cumulative constraint $(\mathrm{N}=3)$. These weights are then applied to model input and output. As said before, equation (1) is either applied to average observations and simulations for the summer 1998 and 1999 period or to subsets (1998 versus 1999, July versus August, working days versus weekend). As we will seen for these different periods, meteorological conditions were different and thus also the information that could be driven from observations. Finally, sensitivity tests with altered pdf's and alters observation uncertainties were performed in order to evaluate the effect of these characteristics on the a posteriori pdf's of anthropogenic emissions.

\section{Results}

3.1. Semiclimatologic Period of Summers $(1998+1999)$

[37] In this section, a posteriori pdf's for anthropogenic emissions will be given for the whole summer 1998 and 1999 period. Figure 4 represents the normalized a priori and a posteriori pdf's for the domain constant variations of $\mathrm{NOx}$ and VOC emissions and also for the VOC/NOx emission ratio. Moreover, changes in the averages and in the standard deviation of the a posteriori pdf's by comparison with the a priori ones are shown (Table 3a). Standard deviations are useful parameters only if distributions are not far from Gaussian. Although no objective analysis was applied in this work to assess this point, it can be stated from visual inspection of Figure 4, that a posteriori pdf's are close to lognormal with a tendency to suppress values far away from the means.

[38] For the summer 1998 and 1999 period, NOx emissions remain nearly unchanged in the a posteriori pdf compared to a priori one, the average correction factor being 1.00 . VOC emissions are enhanced $(+16 \%)$ in the a posteriori pdf, leading also to a stronger VOC/NOx emission ratio $(+16 \%)$. The $1 \sigma$ standard deviations in the a posteriori pdf's are $22 \%$ for NOx emissions, $31 \%$ for VOC emissions, and $33 \%$ for the $\mathrm{VOC} / \mathrm{NOx}$ emission ratio, respectively. These values allow appreciating the uncertainty 

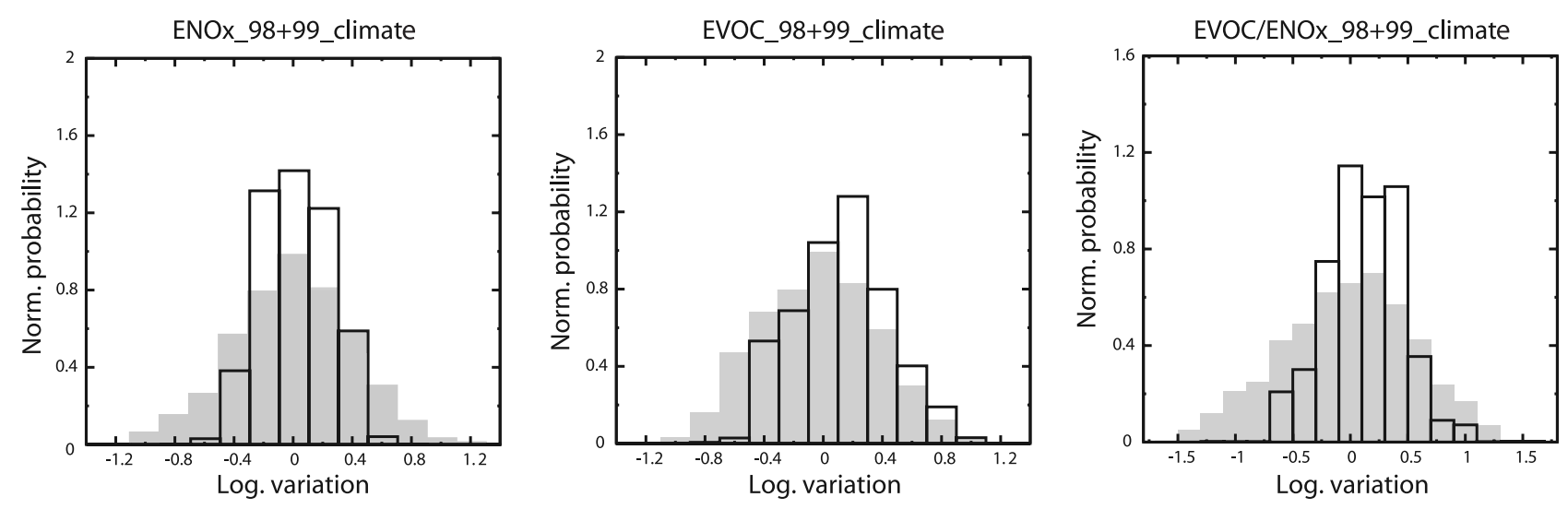

Figure 4. Normalized probability density functions (pdf's) for model input emissions (NOx and volatile organic compounds (VOC)) for summers $1998+1999$. The a priori pdf is represented by the grey histogram; the a posteriori pdf for total constraint is represented by the black histogram. The $\mathrm{x}$ axis shows the logarithmic relative variation for input emissions; that is, \pm 0.3 corresponds to a factor 1.35 increase or decrease.

in inverted emissions, or, more exactly, in the correction factors applied with respect to a priori emissions far from significant at the $2 \sigma$ level. Nevertheless, Table $3 \mathrm{a}$ also shows that the BMC method was very successful in reducing the variance in the emission uncertainty, by nearly $70 \%$ for NOx emissions, by nearly $40 \%$ for VOC emissions and again by nearly $70 \%$ for the $\mathrm{VOC} / \mathrm{NOx}$ emission ratio. We recall that these values are relative to the a priori fixed emission uncertainties of $40 \%$ for NOx and VOC and $56 \%$ for the VOC/NOx ratio (at $1 \sigma$ level).

[39] Next, we analyse how a modification in emissions and eventually other input parameters in the a posteriori pdf's leads to better agreement between simulations and observations (50th percentiles in the cpdf's). Figure 5 represents the cumulative probability density functions (cpdf's) of urban $\mathrm{NO}$, urban $\mathrm{O}_{3}$ and $\mathrm{O}_{3}$ production within the plume. These three values are calculated as described for the set-up of the agreement function (section 2.2.3). The cpdf's not constrained by observations extend over a large range of values. For example, for urban NO, the model allows for very strong NO formation for a number of input parameter sets. When the constraints are taken into account, it appears that the uncertainty in urban NO is reduced by a factor 3.2 in term of the uncertainty range spanned by the 10th and 90th percentiles. For urban NO, the constraint is stronger on the 90th percentiles than on the 10th percentiles so that the cpdf's become more point symmetrical (Figure 5). For urban $\mathrm{O}_{3}$ and $\mathrm{O}_{3}$ production within the plume, this

Table 3a. Modification in A Posteriori Input Parameter Distributions With Respect to the A Priori Ones for Total Constraint and for Summers $1998+1999^{\mathrm{a}}$

\begin{tabular}{lcc}
\hline & \multicolumn{2}{c}{ Total Constraint } \\
\cline { 2 - 3 } Input Parameters & ave $(\mathrm{x})$ and $\sigma(\mathrm{x})(\%)$ & $\Delta(\mathrm{var})(\%)$ \\
\hline NOx emissions & $0 \pm 22$ & -69 \\
VOC emissions & $16 \pm 31$ & -38 \\
EVOC/ENOx & $16 \pm 33$ & -66 \\
\hline
\end{tabular}

${ }^{\mathrm{a}} \mathrm{Ave}(\mathrm{x})$ and $\sigma(\mathrm{x})$ are the average and the standard deviation, respectively; $\Delta$ (var) corresponds to the variance modification between a priori and a posteriori estimates. factor is about 2.4 and 1.7 , respectively, the constraints being lower for the 90th percentiles than for the 10th percentiles. Moreover, these two distributions are shifted to larger values.

[40] We next analyze to what extend the observational constraints improve the agreement between simulations and observations. Table $3 \mathrm{~b}$ represents concentrations of urban $\mathrm{NO}$, urban $\mathrm{O}_{3}$ and $\mathrm{O}_{3}$ production for the reference simulation, for the 50th percentiles in the model output cpdf's from constrained and unconstrained Monte Carlo simulations and from observations. We notice that the simulation of urban NO is already good in the reference simulation. Correspondingly, the constraint applied to Monte Carlo simulations does not strongly modify 50 th percentiles of urban NO. This also explains the fact that NOx emissions remain unchanged in the a posteriori pdf.

[41] Regarding urban $\mathrm{O}_{3}$, the measurement constraint leads to higher modeled than observed concentrations (44.35 versus $42.58 \mathrm{ppb}$ ), overcorrecting to some extent an initial underestimation. Furthermore, the reference CHIMERE model also underestimates $\mathrm{O}_{3}$ production within the plume by a factor of 1.7 compared to observations. When applying the constraint, about half of the difference is removed (Table 3b). This "correction" is mainly due to higher VOC/NOx emission ratios by increasing VOC emissions in the a posteriori distribution, leading to a higher photochemical production of $\mathrm{O}_{3}$. A complete agreement between constraint simulations and observations cannot be expected because of the uncertainty in observations which is taken into account in the agreement function and which allows simulations being within about the $1 \sigma$ range of observations to have a relatively large weight. Indeed, differences between constraint simulations and observations turn out to be always smaller that the $1 \sigma$ uncertainties in observations in this study (for the summer 1998 and 1999 period and for subsets).

\subsection{Differences Between Summers 1998 and 1999}

[42] Table 4a and Figure 6 summarize how a posteriori pdf's for anthropogenic emissions have been modified when applying the measurement constraint separately for 

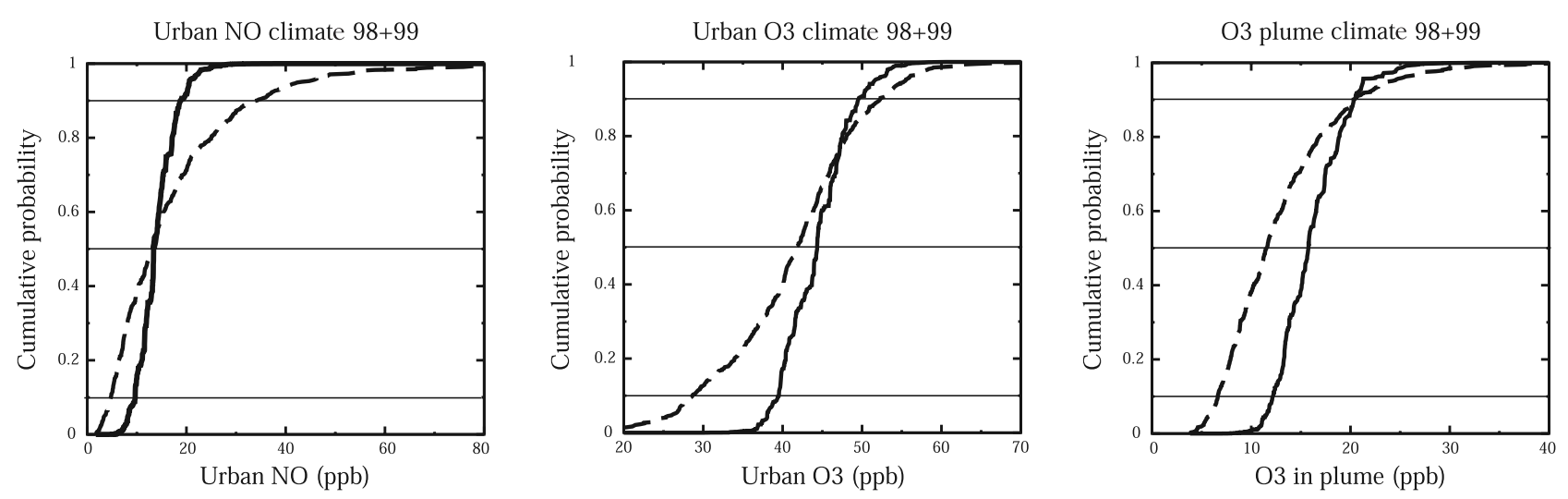

Figure 5. Cumulative probability density functions (cpdf's) for urban $\mathrm{NO}$, urban $\mathrm{O}_{3}$, and $\mathrm{O}_{3}$ production within the plume (dotted line: no constraint; continuous line: total constraint).

summer 1998 and 1999. A posteriori pdf's for NOx emissions in 1998 and 1999 are rather similar. However, VOC emissions are more enhanced in summer 1998 than in summer 1999 (26\% versus 9\%). Consequently, also the VOC/NOx emission ratio is larger for summer 1998 than for summer 1999.

[43] In order to better understand differences between the two summers, we present separate results for each year (Table 4b). We will also distinguish the specific role of different constraints (urban $\mathrm{NO}$ and $\mathrm{O}_{3}$, plume $\mathrm{O}_{3}$ ). For both summers 1998 and 1999, urban NO is most efficient to constrain NOx emissions, their variance being reduced by about $60 \%$ : indeed, urban NO directly contains information on NOx sources within Paris and its near suburbs. For VOC emissions, the most restricting constraint is the $\mathrm{O}_{3}$ production within the plume over the Ile-de-France region. The uncertainty reduction is stronger for summer 1998 than for summer 1999 (Table 4b). Moreover, for summer 1998, the need to correct $\mathrm{O}_{3}$ production within the plume is larger than for summer 1999 (Table 5): 50th percentiles in the model output cpdf's from unconstrained Monte Carlo simulations show a factor 1.9 underestimation with respect to the observed value in 1998, but only a factor 1.5 underestimation in 1999 (leading in fact to the stronger VOC emission enhancement in 1998 than in 1999). The reason for the different behaviour in 1998 and 1999 is not clear. For example, fewer, but more severe pollution episodes were encountered in summer 1998 than in summer 1999. A different intensity of the events could possibly induce different model behaviour, and different biases in model input parameters other than VOC emissions. These uncertainties in model input parameters other than emissions are taken into account in the set-up of the study and contribute to the uncertainty ranges given for a posteriori emissions, about 30\% for VOC emissions $(1 \sigma)$. In light of this value, differences between the 1998 and 1999 corrections are not considered as significant.

[44] Table 5 gives a general overview, how different constraints change output 50th percentiles cpdf's. As can be expected, a particular constraint (i.e., urban NO) pushes cpdf's for the same type of output variable closer to the observed value. However, different constraints can act in different directions: for example, in summer 1998, the " $\mathrm{O}_{3}$ plume" constraint alone leads to a strong overestimation of urban $\mathrm{O}_{3}$ (Table 5). Application of all constraints ("total constraint") leads to a compromise between individual constraints.

\subsection{Stratification Following the Day Type (Working Days Versus Weekend; July Versus August)}

[45] In the following, we report results for different subsets of the two summer period with potentially different emissions correction factors: first, we differentiate between week days and weekend days, second between the July and August period (August being a traditional holiday month). Table 6 summarizes corrections on emissions pointing out that for all subsets, emission corrections and their uncertainty ranges are rather similar. Thus we conclude that the temporal variability (on a day to day and month to month level) is well represented in the initial AIRPARIF cadastre.

\section{Discussion}

\subsection{Other Adjustments of Input Parameters}

[46] In the present work, we focus our attention to the modification of emissions through application of constraints. However, it is expected the other input parameters are modified by the constraints as well. In particular, errors

Table 3b. Agreement Between Simulations and Observations Under Total Constraint and for the Whole Time Period

\begin{tabular}{lcccc}
\hline & & \multicolumn{2}{c}{ P50 } \\
\cline { 2 - 4 } & Reference Simulation & Without Constraint & Total Constraint & Observations \\
\hline Urban NO, ppb & 12.6 & 13.1 & 13.4 & 12.8 \\
Urban $\mathrm{O}_{3}, \mathrm{ppb}$ & 40.6 & 41.7 & 44.3 & 42.6 \\
$\Delta \mathrm{O}_{3}$, plume, pbb & 10.1 & 11.5 & 15.7 & 19.5 \\
\hline
\end{tabular}


Table 4a. Modification in A Posteriori Input Parameter Distributions With Respect to the A Priori Ones for Total Constraint and for Summers 1998 and $1999^{\mathrm{a}}$

\begin{tabular}{lccccc}
\hline Input Parameters & \multicolumn{2}{c}{ Summer 1998 } & & \multicolumn{2}{c}{ Summer 1999} \\
\cline { 2 - 3 } \cline { 5 - 6 } & ave $(\mathrm{x})$ and $\sigma(\mathrm{x})(\%)$ & $\Delta(\mathrm{var})(\%)$ & & ave (x) and $\sigma(\mathrm{x})(\%)$ & $\Delta(\mathrm{var})(\%)$ \\
NOx emissions & $2 \pm 21$ & -70 & & $-1 \pm 23$ & -65 \\
VOC emissions & $26 \pm 30$ & -39 & & $9 \pm 32$ & -34 \\
EVOC/ENOx & $25 \pm 31$ & -70 & & $10 \pm 35$ & -60 \\
\hline
\end{tabular}

${ }^{\mathrm{a}} \mathrm{Ave}(\mathrm{x})$ and $\sigma(\mathrm{x})$ are the average and the standard deviation, respectively; $\Delta$ (var) corresponds to the variance modification between a priori and a posteriori estimates.

in the simulation of horizontal and vertical transport (corresponding to uncertainties in the wind speed, the vertical mixing coefficient and the planetary boundary layer height) are expected to strongly affect simulations and thus to be "corrected" by the observational constraint.

[47] The strongest modification in an input parameter occurred for the vertical mixing coefficient, which decreases by around $20 \%$ in summer 1998 with a variance reduction around $42 \%$. For all other parameters and the year 1999, all adjustments are below $10 \%$. Thus on the whole, adjustments in emissions appear to be the most "efficient" way for the system to better fit the observations.

\subsection{Sensitivity to the Analysis Scheme}

[48] We next identify critical points in the BMC analysis. Sensitivity experiments are performed to test how they affect results. A first uncertainty arises from the somewhat subjective choice of pdf's for the input parameters. Sensitivity experiments with altered pdf's are performed for key input parameters: NOx and VOC emissions. In a first sensitivity experiment, the whole analysis is repeated but with an increased lognormal $1 \sigma$ uncertainty in anthropogenic NOx emission of $44 \%$ instead of $40 \%$ (experiment 1 ). In a second sensitivity experiment, we modify the pdf's of VOC emission in the same way (44\% instead of $40 \%$ ) (experiment 2). Another critical point is the uncertainty in observations used in the agreement function. To test the effect of that uncertainty on BMC analysis, we assume a relative increase in uncertainties in urban $\mathrm{NO}$, urban $\mathrm{O}_{3}$ and $\mathrm{O}_{3}$ production within the plume of $10 \%$ (experiment 3 ). The value of $10 \%$ is completely arbitrary and is only chosen to have a common basis for comparison. This type of experiments does not require new simulations but only the recalculation of the weights attributed to each Monte Carlo simulation.

[49] Table 7 summarizes changes in a posteriori pdf's related to a priori ones for the three different sensitivity experiments. For NOx emissions, a change in the a priori uncertainty range has no effect on the a posteriori uncertainty, whereas a change in the observation uncertainty has at least a small effect. On the contrary, for VOC emissions, the value of the a priori uncertainty has a much stronger influence on the a posteriori uncertainty, whereas the uncertainties in observations only have a small influence. A larger a priori uncertainty also leads to a somewhat larger positive adjustment. In the light of this discussion, results for NOx emissions appear more robust, because they are less dependent on the somewhat arbitrarily chosen values for a priori uncertainties.

\subsection{Comparison With Related Studies}

[50] We now compare results obtained in this study with results obtained from three other studies, all relative to the assessment of uncertainty in emission cadastres in the Ile de France region. In their BMC study, Beekmann and Derognat [2003] also derived correction factors for NOx and VOC emissions in the Ile-de-France region, but their study was restricted to three polluted days, for which well documented airborne $\mathrm{O}_{3}$, NOx, NOy and VOC observations within the plume and in the background air were available from the ESQUIF campaign. For NOx emissions, they found a large scatter in results for individual days varying between $-21 \%$

Table 4b. Modification in A Posteriori Input Parameter Distributions With Respect to the A Priori Ones for Each Constraint and for Summers 1998, 1999, and $1998+1999^{\mathrm{a}}$

\begin{tabular}{|c|c|c|c|c|c|c|c|}
\hline \multirow[t]{2}{*}{ Input Parameters } & \multirow[t]{2}{*}{ Constraints } & \multicolumn{2}{|c|}{ Summer 1998} & \multicolumn{2}{|c|}{ Summer 1999} & \multicolumn{2}{|c|}{ Summer $1998+1999$} \\
\hline & & $\underline{\operatorname{ave}(\mathrm{x}) \text { and } \sigma(\mathrm{x}), \%}$ & $\Delta($ var $), \%$ & ave $(\mathrm{x})$ and $\sigma(\mathrm{x}), \%$ & $\Delta($ var $), \%$ & ave $(\mathrm{x})$ and $\sigma(\mathrm{x}), \%$ & $\Delta($ var $), \%$ \\
\hline \multirow[t]{4}{*}{ NOx emissions } & urban NO & $2 \pm 25$ & -58 & $2 \pm 26$ & -57 & $2 \pm 25$ & -59 \\
\hline & urban $\mathrm{O}_{3}$ & $-4 \pm 34$ & -26 & $-12 \pm 35$ & -24 & $-6 \pm 34$ & -26 \\
\hline & $\mathrm{O}_{3}$ plume & $-3 \pm 35$ & -22 & $-4 \pm 37$ & -14 & $-4 \pm 35$ & -20 \\
\hline & total constraint & $1 \pm 21$ & -70 & $-1 \pm 23$ & -65 & $0 \pm 22$ & -69 \\
\hline \multirow[t]{4}{*}{ VOC emissions } & urban NO & $-1 \pm 37$ & -10 & $-2 \pm 37$ & -11 & $-2 \pm 37$ & -11 \\
\hline & urban $\mathrm{O}_{3}$ & $-2 \pm 36$ & -15 & $0 \pm 37$ & -12 & $-1 \pm 37$ & -14 \\
\hline & $\mathrm{O}_{3}$ plume & $30 \pm 30$ & -39 & $17 \pm 34$ & -26 & $23 \pm 32$ & -31 \\
\hline & total constraint & $26 \pm 30$ & -39 & $9 \pm 32$ & -34 & $16 \pm 31$ & -37 \\
\hline \multirow[t]{4}{*}{ EVOC/ENOx } & urban NO & $-3 \pm 45$ & -36 & $-3 \pm 45$ & -35 & $-3 \pm 45$ & -36 \\
\hline & urban $\mathrm{O}_{3}$ & $1 \pm 47$ & -30 & $11 \pm 47$ & -30 & $5 \pm 47$ & -31 \\
\hline & $\mathrm{O}_{3}$ plume & $33 \pm 48$ & -25 & $21 \pm 49$ & -24 & $26 \pm 48$ & -25 \\
\hline & total constraint & $25 \pm 31$ & -70 & $10 \pm 35$ & -60 & $16 \pm 33$ & -66 \\
\hline
\end{tabular}

${ }^{\mathrm{a}} \mathrm{Ave}(\mathrm{x})$ and $\sigma(\mathrm{x})$ are the average and the standard deviation, respectively; $\Delta$ (var) corresponds to the variance modification between a priori and a posteriori estimates. 

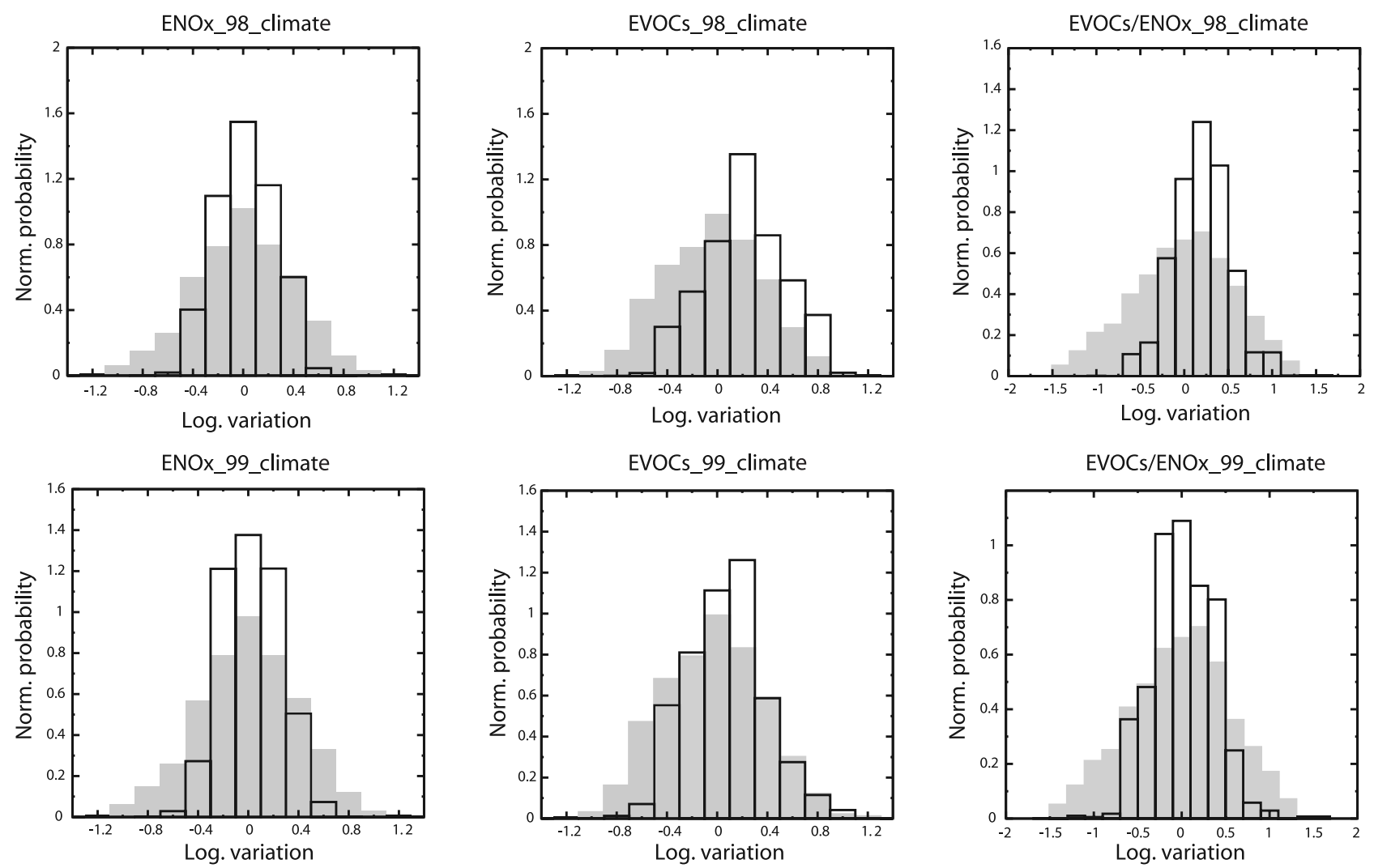

Figure 6. Normalized probability density functions (pdf's) for model input emissions (NOx and VOC) for summers 1998 and 1999. The a priori pdf is represented in the grey histogram; the a posteriori pdf for total constraint is represented by the black histogram.

and $+30 \%$, making it impossible to state about a possible bias in average NOx emissions. The present study removes this uncertainty in analysing a much larger 4 months period and in stating on the absence of a bias. For VOC emissions the Beekmann and Derognat [2003] BMC study yielded corrections between -8 and $+5 \%$, which are fully within the $1 \sigma$ variability of the a posteriori distribution found in the present study $(+16 \% \pm 31 \%)$.

[51] In another study assessing the same Ile-de-France emission cadastre [Vautard et al., 2003b], airborne plume and background NOy and VOC observations obtained during the ESQUIF campaign were used to derive emission correction factors from direct comparison of simulations and observations. Within the statistical uncertainty range of $\pm 35 \%$ for NOx and $\pm 40 \%$ for VOC emissions (at $2 \sigma$ level), no bias in Ile-de-France VOC and NOx emissions was found, in line with results from our study. Again, our study uses a much larger data set (124 days compared to 7 days in the Vautard et al. [2003b] study), making the statistical error a priori negligible with respect to the systematic error in our study.

[52] In a third study, a complementary inversion methodology was developed and applied to the Ile-de-France region for the same summers 1998-1999 period. The

Table 5. Agreement Between Simulations and Observations Under Each Constraint and for Summers 1998, 1999, and 1998 + 1999

\begin{tabular}{|c|c|c|c|c|c|c|c|}
\hline & \multirow[b]{2}{*}{ Reference Simulation } & \multicolumn{5}{|c|}{$\mathrm{P} 50$} & \multirow[b]{2}{*}{ Observations } \\
\hline & & Without constraint & Urban NO & Urban $\mathrm{O}_{3}$ & $\mathrm{O}_{3}$ plume & Total constraint & \\
\hline \multicolumn{8}{|c|}{ Summer 1998} \\
\hline Urban NO, ppb & 13 & 13.6 & 13.7 & 12.4 & 14.7 & 15.1 & 13.3 \\
\hline Urban $\mathrm{O}_{3}, \mathrm{ppb}$ & 41.1 & 41.1 & 41.6 & 41.6 & 48.4 & 44.1 & 40.4 \\
\hline$\Delta \mathrm{O}_{3}$, plume, pbb & 10.2 & 11.1 & 11.6 & 10.7 & 18.5 & 16.9 & 20.8 \\
\hline \multicolumn{8}{|c|}{ Summer 1999} \\
\hline Urban NO, ppb & 12.2 & 12.5 & 12.5 & 9.3 & 12.2 & 12.5 & 12.1 \\
\hline Urban $\mathrm{O}_{3}, \mathrm{ppb}$ & 40.3 & 41.6 & 44.5 & 43.4 & 44.6 & 44 & 43.7 \\
\hline$\Delta \mathrm{O}_{3}$, plume, pbb & 9.9 & 12.1 & 12.8 & 12.5 & 16 & 16 & 18.1 \\
\hline \multicolumn{8}{|c|}{ Summer $1998+1999$} \\
\hline Urban NO, ppb & 12.6 & 13.1 & 13.2 & 11.5 & 13.4 & 13.4 & 12.8 \\
\hline Urban $\mathrm{O}_{3}, \mathrm{ppb}$ & 40.6 & 41.7 & 41.5 & 42.3 & 46.4 & 44.3 & 42.6 \\
\hline$\Delta \mathrm{O}_{3}$, plume, $\mathrm{ppb}$ & 10.1 & 11.5 & 12.2 & 11.6 & 17 & 15.7 & 19.5 \\
\hline
\end{tabular}


Table 6. Modification in A Posteriori Input Parameter Distributions With Respect to the A Priori Ones for Total Constraint for Summers $1998+1999$ With Speciation Between Working Days and Weekend and Between July and August ${ }^{\mathrm{a}}$

\begin{tabular}{|c|c|c|c|c|}
\hline \multirow{2}{*}{$\begin{array}{c}\text { Input Parameters, } \\
\text { Summers } \\
1998+1999 \\
\end{array}$} & \multicolumn{2}{|c|}{ Working Days } & \multicolumn{2}{|c|}{ Weekend } \\
\hline & $\operatorname{Ave}(\mathrm{x})$ and $\sigma(\mathrm{x}), \%$ & $\Delta($ var $), \%$ & ave $(x)$ and $\sigma(x), \%$ & $\Delta($ var $), \%$ \\
\hline NOx emissions & $1 \pm 22$ & -70 & $2 \pm 24$ & -65 \\
\hline VOC emissions & $13.5 \pm 30$ & -41 & $17 \pm 31$ & -38 \\
\hline \multirow[t]{2}{*}{ EVOC/ENOx } & $12 \pm 32$ & -67 & $16 \pm 34$ & -63 \\
\hline & \multicolumn{2}{|c|}{ July } & \multicolumn{2}{|c|}{ August } \\
\hline NOx emissions & $-4 \pm 24$ & -63 & $4 \pm 21$ & -71 \\
\hline VOC emissions & $13 \pm 33$ & -28 & $20 \pm 30$ & -41 \\
\hline EVOC/ENOx & $18 \pm 37$ & -55 & $16 \pm 30$ & -71 \\
\hline
\end{tabular}

${ }^{\mathrm{a}} \mathrm{Ave}(\mathrm{x})$ and $\sigma(\mathrm{x})$ are the average and the standard deviation, respectively; $\Delta(\mathrm{var})$ corresponds to the variance modification between a priori and a posteriori estimates.

method is based on the adjoint model of the CHIMERE model. It was first developed and validated using academic cases [Pison et al., 2006]. During this phase, it was found that only NO surface observations represented the best constraint and allowed to invert spatially aggregated NOx emission fluxes with an hourly time frequency Finally, the methodology was applied over the whole summers of 1998 and 1999 (124 days), as in our study (I. Pison et al., Inversion of surface NOx anthropogenic emissions fluxes in the Paris area during the ESQUIF campaign, submitted to Journal of Geophysical Research, 2006.). The method yields very low average adjustment of NOx emissions (some percent) for the Ile-de-France region, in line with results from our study. Second, intense NOx emissions in the centre of the area are most frequently decreased whereas less intense periurban emissions are increased. For the three types of days (weekday, Saturday and "Sunday or holiday"), the differences between optimized and first-guess profiles are less than $15 \%$, again in line with results from our study.

\section{Conclusions}

[53] We have applied a Bayesian Monte Carlo (BMC) uncertainty analysis to a semiclimatologic period over the Ile-de-France region where photochemical smog formation is often observed [Vautard et al., 2001]. The study aims at inverting anthropogenic NOx and VOC emissions in the Ile-

Table 7. Modification in A Posteriori Input Parameter Distributions With Respect to the A Priori Ones for the Total Constraint and for Summers $1998+1999^{\mathrm{a}}$

\begin{tabular}{ccc}
\hline & \multicolumn{2}{c}{ Total Constraint } \\
\cline { 2 - 3 } Input Parameters & $-0.1 \pm 22.3$ & $\Delta(\mathrm{var})(\%)$ \\
\hline NOx emissions & $-0.1 \pm 22.3$ & -68.7 \\
Experiment 1 & $0.2 \pm 22.3$ & -74.3 \\
Experiment 2 & $-0.3 \pm 22.8$ & -68.7 \\
Experiment 3 & $16.1 \pm 31.5$ & -67.3 \\
VOC emissions & $16 \pm 31.6$ & -36.2 \\
Experiment 1 & $17.7 \pm 33.0$ & -36.2 \\
Experiment 2 & $15.5 \pm 31.9$ & -43.8 \\
Experiment 3 & -35 \\
\hline
\end{tabular}

${ }^{a}$ Experiment 1: $1 \sigma$ uncertainty in anthropogenic NOx emission of $44 \%$ instead of $40 \%$. Experiment 2: $1 \sigma$ uncertainty in anthropogenic VOC emission of $44 \%$ instead of $40 \%$. Experiment 3: An increase in uncertainties on observations of $10 \%$.
de-France region. For cumulative summers $(1998+1999)$, this technique allows obtaining better estimation of NOx and VOC emissions compared to the AIRPARIF a priori ones: (1) The a posteriori pdf for NOx emissions has a nearly unchanged average compared to the a priori one, but a reduced standard deviation (around 20\% compared to $40 \%$ for the a priori one). (2) VOC emissions are enhanced $(+16 \%)$ in the a posteriori pdf with a standard deviation around $30 \%$ (compared to $30 \%$ ). These results imply a stronger VOC/NOx ratio $(+16 \%)$. Those results show the absence of any significant bias in the AIRPARIF emission cadastre. Sensitivity tests with modifications in the BMC method (varying uncertainty range for input parameters and for uncertainty on observations) confirm that the results are more robust for NOx emissions, because they less depend on the choice of their a priori uncertainty.

[54] For future BMC studies, several directions could be taken. First, this type of analysis could be performed over other well documented areas such as the Berre-Marseille region. Measurements performed during the ESCOMPTE campaign [Cros et al., 2004] in the Marseille area and routine data from the AIRMARAIX network could be used for constraining Monte Carlo simulations. However, this area is characterized by complex pollutant circulation due to topography and sea breeze phenomena [Taghavi et al., 2004]. Another possibility could be to apply this method to the continental scale such as over the northwestern Europe [Vautard et al., 2005; Konovalov et al., 2006]. Konovalov et al. [2006] performed original inverse modeling studies using satellite measurements for optimizing spatial distribution of seasonally averaged NOx emissions. BMC analysis could help to better assess the impact of model uncertainty on the inversion of continental-scale NOx emissions.

[55] Acknowledgment. We gratefully acknowledge Pascal Bleuyard for his computer support as well as his input and patience.

\section{References}

Atkinson, R., D. L. Baulch, R. A. Cox, R. F. Hampson, J. A. Kerr, J. M. Rossi, and J. Troe (1997), Evaluated kinetic, photochemical and heterogeneous data for atmospheric chemistry, J. Phys. Chem. Ref. Data, 26, suppl. 5, 521-1012.

Beekmann, M., and C. Derognat (2003), Monte Carlo uncertainty analysis of a regional-scale transport chemistry model constrained by measurements from the atmospheric pollution over the Paris area (ESQUIF) campaign, J. Geophys. Res., 108(D17), 8559, doi:10.1029/ 2003JD003391. 
Bergin, M. S., and J. B. Milford (2000), Application of Bayesian Monte Carlo analysis to a Lagrangian photochemical air quality model, Atmos. Environ., 34, 781-792.

Bessagnet, B., A. Hodzic, R. Vautard, M. Beekmann, S. Cheinet, C. Honoré, C. Liousse, and L. Rouil (2004), Aerosol modelling with CHIMERE: Preliminary evaluation at the continental scale, Atmos. Environ., 38, $2803-2817$.

Brand, K. P., and M. J. Small (1995), Updating uncertainty in an integrated risk assessment: Conceptual framework and methods, Risk Anal., 15 , $719-731$.

Brown, M. (1993), Deduction of emissions of source gases using an objective inversion algorithm and chemical transport model, J. Geophys. Res., 98, 12,639-12,660.

Chang, M. E., D. E. Hartley, C. Cardelino, and W.-L. Chang (1996), Inverse modeling of biogenic isoprene emissions, Geophys. Res. Lett., 23(21), $3007-3010$

Chang, M., D. Hartley, C. Cardelino, D. Haas-Laursen, and W. Chang (1997), On using inverse methods for resolving emissions with large spatial inhomogeneities, J. Geophys. Res., 102(D13), 16,023-16,036.

Cros, B., et al. (2004), The ESCOMPTE Program: An overview, Atmos. Res., 69(3-4), 241-279.

DeMore, W. B., S. P. Sander, D. M. Golden, R. F. Hampson, M. J. Kurylo, C. J. Howard, A. R. Ravishankara, C. E. Kolb, and M. J. Molina (1997), Chemical kinetics and photochemical data for use in stratospheric modelling, eval. 12, JPL Publ., 97-4, 269 pp.

Derognat, C., M. Beekmann, M. Baeumle, D. Martin, and H. Schmidt (2003), Effect of biogenic VOC emissions on tropospheric chemistry during the ESQUIF campaign in the Ile-de-France region, J. Geophys. Res., 108(D17), 8560, doi:10.1029/2001JD001421.

Dilks, D. W., R. P. Canale, and P. G. Meier (1992), Development of Bayesian Monte Carlo techniques for water quality modelling uncertainty, Ecol. Modell., 62, 149-162.

Elbern, H., and H. Schmidt (1999), A four-dimensional variational chemistry data assimilation scheme for Eulerian chemistry transport modeling, J. Geophys. Res., 104, 18,583-18,598.

Elbern, H., H. Schmidt, and A. Ebel (1997), Variational data assimilation for tropospheric chemistry modeling, J. Geophys. Res., 102(D13), $15,967-15,985$.

Enting, I. (2002), Inverse Problems in Atmospheric Constituent Transport, Cambridge Univ. Press, New York.

Friedrich, R. (1997), GENEMIS: Assessment, improvement, temporal and spatial disaggregation of European emission data, in Tropospheric Modelling and Emission Estimation, part 2, edited by A. Ebel, R. Friedrich, and H. Rhode, pp. 181-214, Springer, New York.

Gao, D., W. R. Stockwell, and J. B. Milford (1996), Global uncertainty analysis of a regional-scale gas phase chemical mechanism, J. Geophys. Res., 101, 9107-9120.

Hanna, S. R., J. C. Chang, and M. E. Fernau (1998), Monte Carlo estimates of uncertainties in predictions by a photochemical grid model (UAM-IV) due to uncertainties in input variables, Atmos. Environ., 32, 3619-3628.

Hanna, S. R., Z. Lu, H. C. Frey, N. Wheeler, J. Vukovich, S. Arunachalam, M. Fernau, and D. A. Hansen (2001), Uncertainties in predicted ozone concentrations due to input uncertainties for the UAM-V photochemical grid model applied to July 1995 OTAG domain, Atmos. Environ., 35, $891-903$.

Hartley, D., and R. Prinn (1993), On the feasibility of determining surface emissions of trace gases using an inverse method in a three-dimensional chemical transport model, J. Geophys. Res., 98, 5183-5198.

Konovalov, I. B., M. Beekmann, A. Richter, and J. P. Burrows (2006), Inverse modelling of the spatial distribution of NOx emissions on a continental scale using satellite data, Atmos. Chem. Phys., 6, 1747-1770.

Kühlwein, J., and R. Friedrich (2000), Uncertainties of modelling emissions from road transport, Atmos. Environ., 34, 4603-4610.

Kühlwein, J., R. Friedrich, N. Kalthoff, U. Corsmeier, F. Slemr, M. Habram, and M. Möllmann-Coers (2002), Comparison of modeled and measured total $\mathrm{CO}$ and NOx emissions rates, Atmos. Environ., 36, suppl. 1, S53S60.

Kuhn, M., et al. (1998), Intercomparison of the gas phase chemistry in several chemistry and transport models, Atmos. Environ., 32, 693-709.

Lattuati, M. (1997), Contribution à l'étude du bilan de l'ozone troposphérique à l'interface de l'Europe et de l'Atlantique Nord: Modélisation lagrangienne et mesures en altitude, Ph.D. thesis, Univ. Pierre et Marie Curie, Paris, France.
Madronich, S., and S. Flocke (1998), The role of solar radiation in atmospheric chemistry, in Handbook of Environmental Chemistry, edited by P. Boul, pp. 1-27, Springer, New York.

Mannschreck, K., D. Klemp, D. Kley, R. Friedrich, J. Kuhlwein, B. Wickert, P. Masuska, M. Habram, and F. Slemr (2002), Evaluation of an emission inventory by comparison of modeled and measured emission ratios of individual HC's, CO and NOx, Atmos. Environ., 36, suppl. 1, S81-S94.

Mendoza-Dominguez, A., and A. Russell (2000), Iterative inverse modelling and direct sensitivity analysis of a photochemical air quality model, Environ. Sci. Technol., 34, 4974-4981.

Mendoza-Dominguez, A., and A. Russell (2001), Estimation of emission adjustments from the application of four dimensional data assimilation to photochemical air quality modelling, Atmos. Environ., 35, 2879-2894.

Menut, L. (2003), Adjoint modeling for atmospheric pollution process sensitivity at regional scale, J. Geophys. Res., 108(D17), 8562, doi:10.1029/2002JD002549.

Menut, L., R. Vautard, M. Beekmann, and C. Honoré (2000), Sensitivity of photochemical pollution using the adjoint of a simplified chemistrytransport model, J. Geophys. Res., 105, 15,379-15,402.

Middleton, P., W. R. Stockwell, and W. P. Carter (1990), Aggregation and analysis of volatile organic compound emissions for regional modeling, Atmos. Environ., 24, 1107-1133.

Mulholland, M., and J. Seinfeld (1995), Inverse air pollution modelling of urban-scale carbon monoxide emissions, Atmos. Environ., 29, 497-516.

Pison, I., L. Menut, and N. Blond (2006), Inverse modeling of emissions for local photo-oxidant pollution: Testing a new methodology with kriging constraints, Ann. Geophys., 24, 1523-1535.

Quélo, D., V. Mallet, and B. Sportisse (2005), Inverse modeling of NOx emissions at regional scale over northern France: Preliminary investigation of the second-order sensitivity, J. Geophys. Res., 110, D24310, doi:10.1029/2005JD006151.

Schmidt, H., C. Derognat, R. Vautard, and M. Beekmann (2001), A comparison of simulated and observed ozone mixing ratios for the summer of 1998 in western Europe, Atmos. Environ., 35, 6277-6297.

Schneider, C., C. Kessler, and N. Moussiopoulos (1997), Influence of emission input data on ozone level predictions for the upper Rhine valley, Atmos. Environ., 31, 3187-3205.

Sistla, G., N. Zhou, W. Hao, J.-Y. Ku, S. T. Rao, R. Borstein, F. Freedman, and P. Thunis (1996), Effects of uncertainties in meteorological inputs on urban airshed model predictions and ozone control strategies, Atmos. Environ., 30, 2011-2025.

Slemr, F., R. Friedrichs, and W. Seiler (2002), The research project EVA: General objectives and main results, Atmos. Environ., 36, suppl. 1, $1-6$.

Taghavi, M., S. Cautenet, and G. Foret (2004), Simulation of ozone production in a complex circulation region using nested grids, Atmos. Chem. Phys., 4, 825-838.

Troen, I., and L. Mahrt (1986), A simple model of the atmospheric boundary layer: Sensitivity to surface evaporation, Boundary Layer Meteorol., 37, 129-148.

Vautard, R., M. Beekmann, J. Roux, and D. Gombert (2001), Validation of a hybrid forecasting system for the ozone concentrations over the Paris area, Atmos. Environ., 35, 2449-2461.

Vautard, R., et al. (2003a), A synthesis of the air pollution over the Paris region (ESQUIF) field campaign, J. Geophys. Res., 108(D17), 8558, doi:10.1029/2003JD003380.

Vautard, R., et al. (2003b), Paris emission inventory diagnostics from ESQUIF airborne measurements and a chemistry transport model, J. Geophys. Res., 108(D17), 8564, doi:10.1029/2002JD002797.

Vautard, R., C. Honoré, M. Beekmann, and L. Rouil (2005), Simulation of ozone during the August 2003 heat wave and emission control scenarios, Atmos. Environ., 39, 2957-2967.

Yang, Y.-J., J. Wilkinson, and A. Russel (1997), Fast, direct sensitivity analysis of multidimensional photochemical models, Environ. Sci. Technol., 31, 2859-2868.

M. Beekmann and L. Deguillaume, Laboratoire Inter-Universitaire des Systèmes Atmosphériques, UMR CNRS 7583, Universités Paris 7 et Paris 12, 94010, Créteil Cedex, France. (deguillaume@lisa.univ-paris12.fr)

L. Menut, Institut Pierre Simon Laplace/Laboratoire de Météorologie Dynamique, Ecole Polytechnique 91128 Palaiseau, France. 